\title{
Embryonal Origin of MTSCC of Kidney May Explain its Morphological Heterogeneity: Diagnostic Impact of Genetic Analysis
}

\author{
DANIEL BANYAI ${ }^{1}$, FANNI VASTAG $^{1}$, MARIA YUSENKO $^{2}$, PETER BUGERT $^{3}$ and GYULA KOVACS ${ }^{1,2}$ \\ ${ }^{1}$ Department of Urology, Medical School, University of Pecs, Pecs, Hungary; \\ ${ }^{2}$ Medical Faculty, Ruprecht-Karls-University, Heidelberg, Germany; \\ ${ }^{3}$ Institute of Transfusion Medicine and Immunology, Medical Faculty Mannheim, \\ Heidelberg University and German Red Cross Blood Service Baden-Württemberg - Hessen, Mannheim, Germany
}

\begin{abstract}
Background/Aim: Previous genetic and morphologic characterisation of mucinous tubular and spindle cell carcinoma (MTSCC) have yielded controversial results. The aim of this study was to explain the phenotypic heterogeneity of MTSCC diagnosed by genetic means. Materials and Methods: We analyzed 7 MTSCC by array CGH and microsatellite allelotyping and by histology for morphological variation. We worked-up two entire kidneys with MTSCC to find microscopic alterations. Results: We confirmed the diagnosis of MTSCC by detecting copy number changes at chromosomes $1,4,6,8,13,14,15,18$ and 22. We detected 13 small, microscopic precursor lesions in the two kidneys and found similar histological structures in precursor lesions and MTSCC. Conclusion: MTSCC develops from embryonal rest-like lesions of impaired differentiation which may explain its morphological variations. Until diagnosis of a "malignant" MTSCC" is not confirmed by genetic means, it should not be called carcinoma.
\end{abstract}

The definition of mucinous tubular and spindle cell carcinoma (MTSCC), a rare neoplasm of the kidney, is descriptive: "renal epithelial neoplasm characterized by tubular formations merging with bland spindle cells and a myxoid stroma" (1). However, several MTSCC do not show mucinous changes or spindle cell pattern, but rather tubular

Correspondence to: Gyula Kovacs, Department of Urology, Medical School, University of Pecs, Munkacsy M. u. 2, H-7621 Pecs, Hungary. Tel: +36 72507334, Fax: +36 72242374, e-mail: G.Kovacs@gmx.de; gyula.kovacs@urz.uni-heidelberg.de

Key Words: Mucinous tubular and spindle cell carcinoma, morphological heterogeneity, precursor lesion, array $\mathrm{CGH}$, microsatellite analysis. and papillary structures of small or medium size basophilic or eosinophilic cells. Some cases display focal foamy cell infiltration, psammoma bodies or inflammation, changes which are frequently seen in papillary renal cell tumours (RCT) (2). Based on similarity, it was proposed that MTSCC is a variant of papillary RCT $(3,4)$. Pathologists with limited experience in histopathology of renal neoplasms might be confronted with the differential diagnosis between MTSCC with tubulo-papillary growth pattern and papillary RCT. Although MTSCC is considered a benign tumour, cases with high-grade and sarcomatoid changes or metastatic growth have been reported (5-8). Case reports and small series of so-called "non-classical" MTSCC with variable immunohistochemical characteristics without any diagnostic impact have also been described $(9,10)$. As no reliable markers have been identified, the published data on immunohistochemistry of MTSCC are controversial $(11,12)$.

Comprehensive genetic studies detected alteration of chromosomes $1,4,6,8,13,14,15,18$ and 22 to be specific for MTSCC (Table I) (13-15). The objective of our study was to describe the morphological heterogeneity of MTSCCs diagnosed unequivocally by high resolution array $\mathrm{CGH}$ and call the attention to their embryonal origin.

\section{Materials and Methods}

Tissue samples and DNA isolation. Five MTSCC cases were selected from the archive of the Department of Urology whereas the remaining two cases were seen in consultation. The age of patients varied between 42 and 62 , the size of tumours between 35 and 80 $\mathrm{mm}$, five tumours were obtained from females and two from males. From one of the cases both kidneys were available and embedded completely in 47 and 67 paraffin blocks. High molecular weight DNA was isolated from frozen tissues of two MTSCCs by phenol/chloroform treatment after proteinase $\mathrm{K}$ digestion. In the 5 cases DNA was isolated from formalin fixed and paraffin embedded (FFPE) samples as described earlier (16). The use of tissue samples 
Table I. Specific genetic alterations detected in MTSCC: review of the literature.

\begin{tabular}{|c|c|c|c|c|}
\hline No. of cases & Chromosomal changes & Diagnosis & Methods & Reference \\
\hline 5 & $-1,-4,-6,-8,-9,-13,-14,-15,-22$ & MTSCC & chrCGH, MS & Rakozy et al. (13) \\
\hline 1 & $-1,-4,-6,-8,-9,-13,-14,-15,-22$ & MTSCC & CHR & Ferlicot et al. (14) \\
\hline 9 & $-1,-3,-6,-8,-9,-13,-14,-15,-22$ & MTSCC & $\mathrm{aCGH}$ & Peckova et al. (15) \\
\hline 7 & $-1,-4,-6,-8,-9,-13,-14,-15,-22$ & MTSCC & $\mathrm{aCGH}$ & Present study \\
\hline 3 & $\begin{array}{c}-1,-4,-6,-9,-13,-14,-15,-18,-22 \\
-1,-4,-6,-9,-13,-14,-15,-18,-22 \\
-1,-6,-8,-11,-14,-15,-22\end{array}$ & $\mathrm{CDC}$ & CHR & Fuzesi et al. (18) \\
\hline 1 & $-1,-3,-4,-6,-9,-11,-13,-14,-15,-17,-21,-22$ & $\mathrm{CDC}$ & CHR & Antonelli et al. (19) \\
\hline
\end{tabular}

CHR: Chromosome analysis; MS: PCR-based microsatellite analysis; chrCGH: chromosomal CGH; aCGH: array CGH; CDC: collecting duct carcinoma.

for this study was approved by the Ethics Committee of the University of Heidelberg.

DNA array based comparative genomic hybridisation (CGH). The high molecular genomic DNA was hybridized to a $105 \mathrm{k}$ microarray platform whereas the DNA extracted from FFPE tissues was subjected to 44k CGH microarray platform (Agilent Technologies, Waldbronn, Germany) according to the procedure of manufacturer's version 5.0 as described previously (16). Scanning and image analysis were carried out on a DNA Microarray Scanner (Agilent Technologies) according to the user's guide (version 2.0 or 5.0). The Agilent Scanner Control software (version 7.0) was used for the 5 $\mu \mathrm{m}$ scan resolution with $100 \%$ PMT for both channels. Feature Extraction Software (version 9.5) was used for data extraction from raw microarray image files using grid template AMADID 014950 for $44 \mathrm{k}$ arrays and AMADID 014950 for 105k arrays. To visualise, detect, and analyse chromosomal patterns within the microarray profiles CGH Analytics Software (Agilent Technologies) was used. Global ADM 2 algorithm with a threshold 6.0 and aberration filter defaulted for minimum 3 probes in region was applied for the analysis.

Microsatellite analysis. Genomic DNA extracted from normal and tumor tissue samples was subjected to PCR-based amplification of microsatellite loci using flanking primers. Four multiplex reactions included primers for amplification of all loci (multiplex \#1: D3S1358, D18S51, D21S11; multiplex \#2: TPOX, FGA, D5S818, D7S820, D13S317, PentaE, D16S539; multiplex \#3: D1S1656, D8S1179, D10S1248, D12S391, D19S433, D22S1045; multiplex \#4: D1S214, D1S2799, D9S157, D9S201, D9S1748). Electrophoresis and detection of fluorescently labeled PCR products was performed on a LI-COR 4300 DNA fragment analysis system.

\section{Results}

Genomic changes of diagnostic impact in MTSCC. All genomic changes detected by array $\mathrm{CGH}$ involved entire chromosomes (Figure 1A). We did not find copy number changes at small genomic regions by applying the $105 \mathrm{k}$ micro array platform with an average spatial resolution of $\sim 15 \mathrm{~kb}$. Evaluating the results obtained by array CGH and microsatellite allelotyping (Figure 1B), we confirmed the specific alteration of chromosomes $1,4,6,(8), 9,13,14,15$, and 22 in each MTSCC.

Precursor lesions associated with MTSCC. Detailed microscopic examination of 114 paraffin blocks of two kidneys of a patient with MTSCC revealed 13 small microscopic lesions. Eleven of them displayed tubular and papillary structures intermingled with normal kidney parenchyma (Figure 2a and b). Two lesions were composed of tubular formations of small cells showing occasionally glomerulus-like structures embedded in myxoid-oedematous stroma (Figure 2c). Similar lesions were also seen in clinically detected MTSCC (Figure 2d-f).

Morphological heterogeneity of MTSCC. Microscopic evaluation revealed spindle cell growth together with elongated tubular pattern in four tumours. Variable amount of mucinous matrix was seen in 3 of the 7 cases (Figure $2 \mathrm{~g}$, $\mathrm{h}$ and $\mathrm{j}$ ). Tumour cells displayed mucin in cytoplasm but not in the stroma in one MTSCC (Figure 2i). Psammoma bodies and foamy macrophages were noticed in three tumours. Focal papillary growth of small "blue" cells was seen in two cases (Figure $2 \mathrm{~d}$ and e) whereas one tumour revealed glomeruloid bodies similar to that seen in precursor lesions (Figure 2f). Papillary formations mixed with slightly dilated tubular structures were seen in 3 tumours (Figure 2k and 1).

\section{Discussion}

Copy number changes along the entire chromosomes 1, 4, 6, (8), 9, 13, 14, 15 and 22 without small genomic changes confirmed the diagnosis of MTSCC in the 7 cases subjected to this study. The novel finding of this study is the detection of small precursor lesions associated with MTSCC. The similarity of morphological variations in precursor lesions and clinically recognised MTSCC strongly suggest that MTSCC develops from such lesions. In 1882 Cohnheim has postulated 


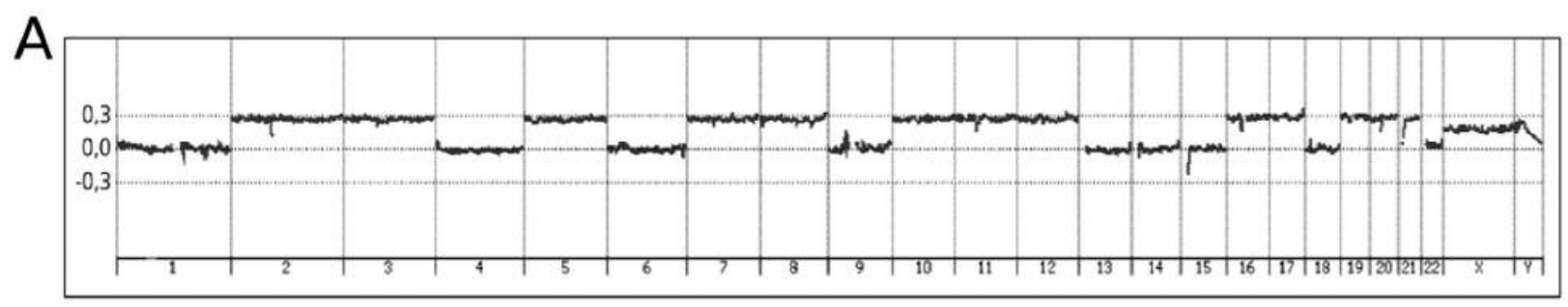

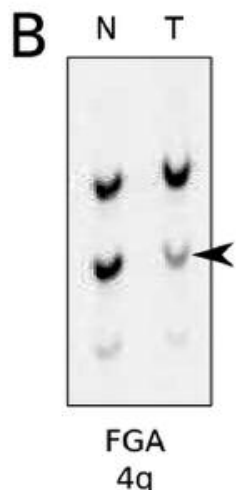
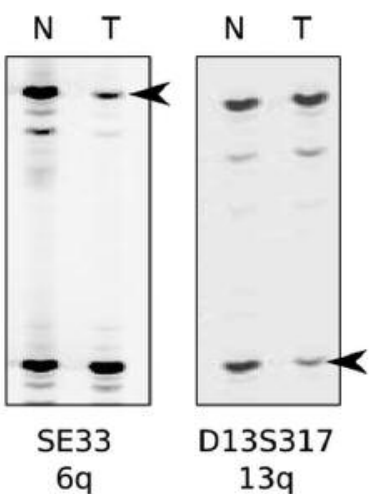

$13 q$

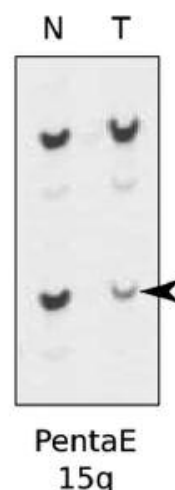

$15 q$

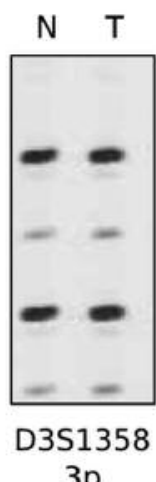

$3 p$

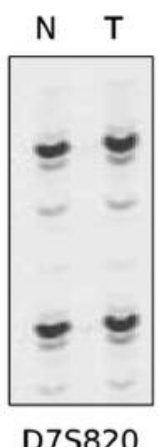

$7 q$

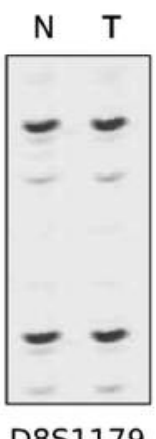

D8S1179

$8 \mathrm{q}$

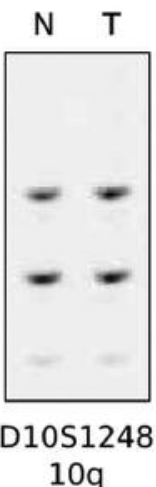

$10 \mathrm{q}$

Figure 1. Results of array CGH and microsatellite allelotyping. Representative profile showing copy number alterations at chromosomes 1, 4, 6, 9, 13, 14, 15, 18 and 22 obtained by hybridization of high molecular weight DNA to the 105k array platform. The allelic changes at specific chromosomes (arrow heads) were confirmed by microsatellite analysis as well.

that "an error and disregulation" in the embryonal Anlage may lead to development of tumours (17). Wilms' tumour (WT) and papillary RCT have already been recognized as a useful model to explore the tumour development from "not differentiated superabundant" embryonal rest cells $(18,19)$. Now, we add MTSCC to this group of tumours. WT, MTSCC and papillary RCT display morphological variations corresponding to impaired differentiation of blastemal cells, albeit at different time of mesenchyme to epithelium transition affecting different cell lineages (19). The embryonal origin of MTSCC may explain its morphological variations making the diagnosis uncertain in some cases.

Over the last years, the histological spectrum of MTSCC was extended with so-called "non-typical" forms or malignant MTSCCs as well as "hybrid" tumours and the list of unusual forms published in the literature is growing (2-10). However, none of the "malignant" MTSCC was confirmed by genetic analysis. Earlier, genetic alterations specific for MTSCC have been described in 4 renal cell tumours diagnosed as collecting duct carcinoma, a highly malignant tumour (Table I) $(20,21)$. With all certainty, these cases correspond to MTSCC and were misdiagnosed as collecting duct carcinoma. In a recent study of 45 histologically-diagnosed MTSCC with "uniform morphologic pattern" eleven cases were successfully analyzed by array $\mathrm{CGH}$ and 2 of them revealed chromosomal gains, the hallmark of papillary RCTs (15). The results of this study warrant caution when diagnosing MTSCC. Until DNA techniques applied, cases of "non-typical", "hybrid" or "malignant" MTSCCs remain somewhat questionable.

In conclusion, we described the morphological heterogeneity of genetically diagnosed MTSCC and connected the development of this rare type of tumour to impaired embryonal development. We suggest that until the diagnosis of "malignant" MTSCC" will not be confirmed by genetic means, it should not be called carcinoma. To avoid any confusion on the biological nature of "MTSCC", it would be better to change the descriptive diagnosis to "mucinous, tubular and spindle cell tumor" (MTSCT).

\section{Conflicts of Interest}

The Authors have no conflicts of interest to declare.

\section{Acknowledgements}

This study was partly supported by a grant from the Medical Faculty of the University Pecs, Hungary (PTE-AOK KA 2014-1). The Authors thank Drs. Börje Ljungberg and Laszlo Füzesi for providing fresh tumour tissues. The present contribution is dedicated to the 650th anniversary of the foundation of the University of Pecs, Hungary. 

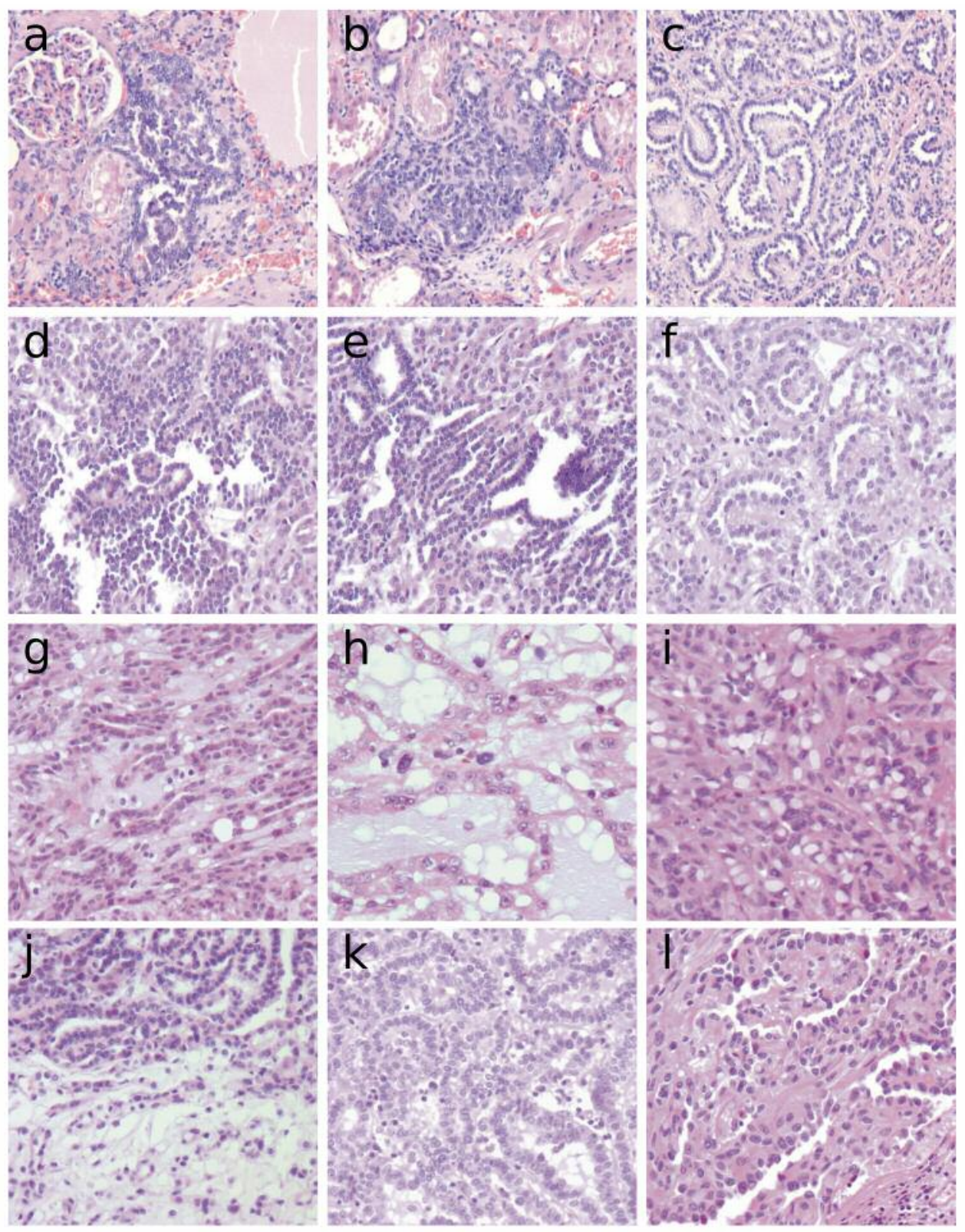

Figure 2. Morphological heterogeneity of precursor lesions and MTSCCs. Tubulopapillary growth of small cells in precursors ( $a$ and b) and MTSCCs $(d$ and e). Abortive glomerular structures in precursor lesion $(c)$ and MTSCC $(f)$. Elongated tubular structures $(g)$ and also cords of epithelial cells with variable nuclear size and prominent nucleoli $(h)$ or dissociated single cells $(j)$ are embedded in mucinous matrix. Solid growth of cells displaying mucin in cytoplasm ( $i)$. Tubular papillary growth with less or more fibrotic stroma ( $k$ and $l$ ).

\section{References}

1 Moch H, Humphrey PA, Ulbright TM and Reuter VE (Eds): WHO Classification of tumours of the urinary system and male genital organs (4th edition). IARC: Lyon 2016.

2 Fine SW, Argani P, DeMarzo AM, Delahunt B, Sebo TJ, Reuter VE and Epstein JI: Expanding the histologic spectrum of mucinous tubular and spindle cell carcinoma of the kidney. Am J Surg Pathol 30: 1554-1560, 2006.
3 Argani P, Netto GJ and Parwani AV: Papillary renal cell carcinoma with low-grade spindle cell foci: a mimic of mucinous tubular and spindle cell carcinoma. Am J Surg Pathol 32: 1353-1359, 2008.

4 Shen SS, Ro JY and Tamboli P: Mucinous tubular and spindle cell carcinoma of kidney is probably a variant of papillary renal cell carcinoma with spindle cell features. Ann Diagn Pathol 11: 13-21, 2007.

5 Pillay N, Ramdial PK, Cooper K and Batuule D: Mucinous tubular and spindle cell carcinoma with aggressive histo- 
morphology - a sarcomatoid variant. Hum Pathol 39: 966-969, 2008.

6 Dhillon J, Amin MB, Selbs E Turi GK, Paner GP and Reuter VE: Mucinous tubular and spindle cell carcinoma of the kidney with sarcomatoid change. Am J Surg Pathol 33: 44-49, 2009.

7 Kuroda N, Naroda T, Tamura M, Taguchi T, Tominaga A, Inoue $\mathrm{K}$, Shuin T, Lee $\mathrm{GH}$, Hes $\mathrm{O}$ and Michal M: High-grade mucinous tubular and spindle cell carcinoma: comparative genomic hybridization study. Ann Diag Pathol 15: 472-47, 2011.

8 Thway K, du Parcq J, Larkin JMG, Fisher C and Livni N: Metastatic renal mucinous tubular and spindle cell carcinoma. Atypical behavior of a rare, morphologically bland tumor. Ann Diagn Pathol 16: 407-410, 2012.

9 Alexiev BA, Burke AP, Drachenberg CB, Richards SM andZou YS: Mucinous tubular and spindle cell carcinoma of the kidney with prominent papillary component, a non-classic morphologic variant. A histologic, immunohistochemical, electron microscopic and fluorescence in situ hybridization study. Pathol Res Practice 210: 454-458, 2014.

10 Farghaly H: Mucin poor mucinous tubular and spindle cell carcinoma of the kidney, with nonclassic morphologic variant of spindle cell predominance and psammomatous calcification. Ann Diag Pathol 16: 59-62, 2012.

11 Reuter V, Argani P, Zhou M, Delahunt B and ISUP: Best practices recommendations in the application of immunohistochemistry in the kidney tumors. Am J Pathol 38: 35-49, 2014.

12 Zhao M, He X and Teng X: Mucinous tubular and spindle cell renal cell carcinoma: a review of clinicopathologic aspects. Diagn Pathol 10: 168, 2015.

13 Rakozy C, Schmahl GE, Bogner S and Stoerkel S: Low-grade tubular-mucinous renal neoplasms: morphologic, immunohistochemical, and genetic features. Mod Pathol 15: 1162-1171, 2002.

14 Ferlicot S, Lupo A, Lazure T, Bedossa P and Vieillefond A: A novel entity: low grade mucinous tubular renal carcinoma. Histopathology 47: 218-219, 2005.
15 Peckova K, Martinek P, Sperga M, Montiel DP, Daum O, Rotterova P, Kalusová K, Hora M, Pivovarcikova K, Rychly B, Vranic S, Davidson W, Vodicka J, Dubová M, Michal M and Hes O: Mucinous spindle and tubular renal cell carcinoma: analysis of chromosomal aberration pattern of low-grade, high-grade, and overlapping morphologica variant with papillary renal cell carcinoma. Ann Diagn Pathol 19: 226-231, 2015.

16 Szponar A, Yusenko MV and Kovacs G: High-resolution array CGH of metanephric adenomas: lack of DNA copy number changes. Histopathology 56: 212-216, 2010.

17 Cohnheim J: Vorlesungen über allgemeine Pathologie. August Hirschwald p.737, Berlin, Germany, 1882.

18 Beckwith JB, Kiviat NB and Bonadio JF: Nephrogenic rests, nephroblastomatosis, and the pathogenesis of Wilms' tumor. Fetal and Pediatric Pathology 10: 1-36, 1990.

19 Szponar A and Kovacs G: Expression of KRT7 and WT1 differentiate precursor lesions of Wilms' tumours, papillary renal cell tumours and mucinous tubular and spindle cell carcinomas. Virchows Arch 460: 423-427, 2012.

20 Fuzesi L, Cober $\mathrm{M}$ and Mittermayer C: Collecting duct carcinoma: cytogenetic characterization. Histopathol 21: 155$160,1992$.

21 Antonelli A, Portesi E, Cozzoli A, Zanotelli T, Tardanico R, Balzarini P, Grigolato PG and Cosciani Cunico S: The collecting duct carcinoma of the kidney: A cytogenetical study. Eur Urol 43: 680-685, 2003.
Received January 27, 2017

Revised February 26, 2017

Accepted February 26, 2017 